\title{
Study on the Path Design of Integrating Innovation and Entrepreneurship Education into Nursing Professionals
}

\author{
Meiqian Li, Liqun Yang \\ Liaoning Province Meteorological Information Center, Shenyang, Liaoning, 161006
}

Keywords: innovation and entrepreneurship education; nursing specialty; talent cultivation; path

\begin{abstract}
The whole process of integrating innovation and entrepreneurship education into the training of nursing professionals will help deepen the reform of nursing education and teaching, improve the quality of education and teaching, and help foster innovative nursing talents. This paper analyzes the significance, theoretical basis and factual basis of innovation and entrepreneurship education, and puts forward the path and method of integrating innovation and entrepreneurship education into the whole process of nursing professional training.
\end{abstract}

\section{Introduction}

The Ministry of Education's "Opinions on Vigorously Promoting Innovation and Entrepreneurial Education in Colleges and Universities and Self-starting Work for College Students" issued in 2010 pointed out that innovation and entrepreneurship education should be oriented toward all students and be integrated into the entire process of talent cultivation. Based on professional education, we must take the lead in changing education ideas and updating educational concepts. We must focus on improving students' sense of social responsibility, innovation, entrepreneurship, and entrepreneurship. We must focus on reforming the personnel training model and curriculum system, and vigorously promote higher education. School innovation and entrepreneurship education, and constantly improve the quality of personnel training. In order to thoroughly implement the relevant policies and guidelines of the Ministry of Education, our school has achieved remarkable results in innovation and entrepreneurship education for undergraduates in recent years. We now report the path design of the innovation and entrepreneurship education in our hospital as part of the training process for nursing professionals. .

\section{Implementation Significance and Purpose}

It is conducive to the in-depth implementation of the national education policy. The Ministry of Education issued in 2010 the Opinions on Promoting Innovation and Entrepreneurial Education in Colleges and Universities and the Self-starting Work for College Students, and the Outline of the National Medium- and Long-Term Education Reform and Development Plan (2010-2020) clearly stated that it is necessary to vigorously promote College Innovation and Entrepreneurship Education. The State Council issued the "Implementation Opinions of the General Office of the State Council on Deepening the Reform of Innovation and Entrepreneurship Education in Colleges and Universities” (Guobanfa [2015] No. 36). Heilongjiang Province has also issued relevant policies.

Innovation and Entrepreneurship Education The integration of nursing professionals in the entire process of training will help deepen the reform of nursing education and improve the quality of education and teaching.

Practice the "Three-oriented" nursing professional training model in our hospital and deeply implement the "student-centered" education and teaching concept.

The nursing specialty of our school passed the professional certification of the Ministry of Education in 2015. In 2016, it was subject to national review and evaluation. The combination of evaluation and promotion, evaluation and construction, and rectification-construction-research-to promote organic integration are conducive to the development of disciplines and professional development. 
The demand of the nursing industry at home and abroad requires that the talents cultivated by the higher nursing specialty have a certain degree of professional competitiveness. The integration of innovation and entrepreneurship education provides effective training for occupational attitudes, professional qualities, professional emotions, professional ethics, and occupational competence throughout the entire process. Approaches and platforms.

It is conducive to the development of the general education curriculum, medical basics, nursing professional teachers and improve the quality and ability.

\section{Theoretical Basis and Factual Basis of the Research}

Comprehensively develop education theories. Based on the Marxist doctrine of "the all-round development of man's ideals", it mainly understands the overall development of man from the following two aspects: First, the combination of man's mental work and physical labor, and the realization of so-called moral education, intellectual education, sports, Aesthetic education and the development of labor and technical education are all-rounded. Second, the talents and qualities of a complete individual can be fully and harmoniously developed.

Personality Education Theory. The theory of personalized education emphasizes the differentiation and individualization of education subjects. Each individual will have individual differences due to factors such as hereditary characteristics, personality trends, and growth processes. Individualized education recognizes the diversity of the educated person in all aspects, and based on these individual differences and the physical and mental The law of development, through the manifestation of its distinct and distinct personalities at all levels of education, is aimed at formulating individual-specific education methods and content and developing individualized education.

Cooperative education theory. Cooperative education is a unique advantage in making full use of various educational environments and educational resources such as schools, enterprises, and scientific research, as well as their respective skills, capital, and knowledge in personnel training to improve the overall quality of students and improve students' Comprehensive ability and enhancing the employment competitiveness of students as the key cooperative education promotes the equality of teachers and students.

The subject education theory. It refers to the education of one subject to cultivate another subject, emphasizing initiative, autonomy and creativity. The goal is to enable students to develop comprehensively, freely, and fully. The theory's value position is to exert the subjectivity of both the teaching subject and the subject of the subject, while promoting the subjectivity of the student, so as to achieve the purpose of cultivating creative talents.

\section{Definition of Core Concepts in Research}

Innovation Education. The original meaning of innovation includes three aspects: first, updating; second, creating new things; third, changing. The definition of innovative education in the academic world is divided into two categories: the definition of narrow sense holds that it is an educational activity with the purpose of cultivating innovative spirit, consciousness, personality, thinking and creativity; the broad definition refers to all aspects of cultivating a person's innovative qualities and enhancing innovation. New educational activities for capacity. Innovation education is a kind of education that aims to cultivate people's innovative spirit and innovative ability.

Entrepreneurship education. It was first proposed by Colin Bol, an expert from the World Organization for Economic Cooperation and Development, at the UNESCO International Symposium on Education held in Beijing in November 1989. He proposed the concept of "three passports," in which the "third education passport" is "entrepreneurial education." This is the first time that the concept of entrepreneurship education has emerged. Other scholars understand entrepreneurship education in a broad sense, and believe that entrepreneurship education is to cultivate people's innovative and pioneering qualities.

Innovation and Entrepreneurship Education. China has integrated the concept of innovation into 
the concept of entrepreneurship education and put forward the concept of innovation and entrepreneurship education. This is a brand-new educational concept formed by the development of higher education adapted to economic and social development. Several representative viewpoints are as follows: Innovation and entrepreneurship education is a basic value orientation in order to cultivate students' innovation and entrepreneurship, shape students' innovation and entrepreneurial personality, enhance students' innovative and entrepreneurial quality, and improve students' innovation and entrepreneurial ability. Educational activities. Its core connotation is: taking the transformation of traditional educational thoughts, backward and outdated educational concepts as a guide, innovation and entrepreneurship education in combination with professional education, the whole process for all students in colleges and universities, and integration into the entire process of personnel training as a basic principle to shape students' innovation and entrepreneurship. Personality, improve students' comprehensive quality of innovation and entrepreneurship, improve students' ability of innovation and entrepreneurship as the core, focus on reform and innovation personnel training model, and constantly improve the quality of innovation and entrepreneurship training. In 2015, the State proposed innovation and entrepreneurship education to be oriented toward all students and integrated into the entire process of talent cultivation.

"Three-oriented" nursing talent training model. As an undergraduate medical college with distinctive characteristics, the reform and innovation of the applied medical personnel training system have been continuously carried out for many years. Based on medical education standards, a three-oriented talent training model with the goal of student's future development has been constructed. The three-oriented nursing talent training model consists of three parts: one is the humanistic quality education oriented by professional emotions; the other is the cultivation of professional qualities guided by professional competence; and the third is the cultivation of physical and mental qualities guided by social adaptation.

\section{Effective Implementation Plan}

Complete revision of nursing professional training program. Training objectives: To develop to meet the needs of the development of health care, to systematically master basic theories, basic knowledge, and basic skills of medicine, nursing science, humanities and social sciences, preventive health care, and to have basic clinical nursing abilities, preliminary teaching abilities, and management Ability and scientific research ability, and life-long learning ability and good professional quality, in line with the "three-oriented" personnel training model requirements, can be applied in all types of health care, health care institutions engaged in clinical nursing, preventive care, community nursing professional nursing professional talents . Construct a "five-oriented" four-module curriculum system for nursing specialty. In accordance with the "three-oriented" nursing professional training model requirements, according to the national nursing professional education standards, adhere to the goal of comprehensive development of students, optimize the integration of the curriculum system, adhere to the integration of the curriculum system, part-time "five combination" principle, that is, theory and Combining practice items, combination of extracurricular and extracurricular activities, integration of commonalities and individualities, integration of humanities and sciences, and a combination of on-campus and off-campus principles break the traditional three-stage curriculum setting system. Four teaching modules were constructed, and compulsory courses, elective courses and extracurricular time were integrated into each teaching module to form a complete course system that was horizontally and vertically interwoven into a network. The training program has added extracurricular practical teaching management links including early contact with the clinic, early contact with the society, and early contact with scientific research.

Based on the "three-oriented" nursing talent education model, the innovation and entrepreneurship teaching model was constructed from the four aspects of teaching objectives, curriculum setting, teaching methods and evaluation systems.

Reform teaching methods in education. PBL, case-based teaching, flipping classroom, experiential teaching, and situational teaching are used in the teaching of nursing specialty courses 
to cultivate students' ability to find problems, analyze problems and solve problems, and cultivate students' independent learning ability and team awareness. At the same time, focus on critical thinking training.

Widely carry out innovation and entrepreneurship practices. By participating in the national, provincial, and school organization of innovation and entrepreneurship contests, lectures, forums, and simulations, students can enrich their knowledge and experience in innovation and entrepreneurship, and improve their innovative spirit and entrepreneurial ability. Provincial innovation and entrepreneurship education and practical activities are organically combined.

Construction of a school business startup base. Use bases to conduct entrepreneurship training. It is necessary to actively integrate all aspects of resources in schools and affiliated hospitals, and to explore and develop training programs for college students in medical colleges.

\section{Acknowledgements}

Fund Project: Key Project Number of Heilongjiang Province Education Plan 2016 (GJB1316111)

\section{References}

[1] Liu Jicheng, Zhang Xiaojie, Yun Changhai et al. Exploration and Practice of the Reform of the Three-Directed Talent Cultivation Model with the Objective of Medical Students' Future Development[J]. China Higher Medical Education, 2014, (4):1-2.

[2] Cui Guangcheng, Zhang Xiaojie, Bai Li et al. Reform and practice of medical humanistic quality cultivation based on professional emotion orientation[J]. China Higher Medical Education, 2014, (4):3-4.

[3] Zhang Xiaojie, Yun Changhai, Luo Qingdong et al. Research and Practice of Professional Quality-oriented Professional Quality Training [J]. China Higher Medical Education, 2014, (4): 5-6.

[4] Chen Xuefang, Zhang Yiping. Thoughts on the integration of entrepreneurship education to inform the whole process of talent cultivation [J]. China Electric Power Education, 2009,136:67-68

[5] Shi Xiaojuan, Huang Junyan, Wang Xiaomin. Practice and Analysis of Innovative and Entrepreneurial Education in Applied Specialty[J]. Laboratory Science, 2015, 18(2) 119-121

[6] Sun Ping, Sun Dandan. Cultivation of Undergraduates' Innovation and Entrepreneurial Ability Based on Talent Cultivation Model [J]. Shanxi Science and Technology. 2014, 29(1)104-106 